\title{
Blended Learning with Smartchoice iTools
}

\author{
Elvina Arapah \\ English Department \\ Universitas Lambung Mangkurat \\ Banjarmasin, Indonesia \\ elvteen1327@gmail.com
}

\begin{abstract}
Lembaga Bahasa dan Pendidikan Profesional (LBPP) LIA has made use of a blended learning type. It is a face-to-face training combined with self-paced e-learning from Smart Choice Series equipped with iTools. These materials are already in use for almost four years and are approaching the ending or evaluation time for the materials' usage. This research investigated the utilizations of itools' features by the teachers in terms of the knowledge and the frequency. The respondents were 14 teachers of LBPP LIA Banjarmasin and Banjarbaru and they have ever taught the level of Elementary (EI) and Intermediate (In) using the Smart Choice iTools. Quantitative data were collected through questionnaire in April on Term II of 2017. This study serves as an early and partial evaluation on the implementation of blended learning by utilizing the Smart Choice iTools. The results showed that some features are elaborated to the fullest meanwhile at the same time, some others are not frequently in use. These conditions might be due to the teachers' knowledge of the features or the activities carried out during the sessions.
\end{abstract}

Keywords-Blended Learning, Features, Smart Choice itools

\section{INTRODUCTION}

The emergence of sophisticated and virtual media has led a change to traditional classroom that relies mostly on the white/blackboard and chalk as the teaching and learning media. The use of laptop and LCD has replaced the task of Overhead Projector (OHP) that made use transparent plastics as the spreadsheet. The growing utilization of e-book has altered the physics of thick and heavy books. Moreover, the printed Encyclopedia has already been replaced by the online dictionary or internet based Encyclopedia. All in all, there have been many more development or improvement in the classroom due to the positive use of $21^{\text {st }}$ century media.

Related to the increasing utilization of teaching and learning media, being technology savvy is mostly required. According to Tate [1], media literacy is more than the capacity to access, analyze, evaluate, and communicate messages, media literacy gives students and teachers the opportunity to examine the sociopolitical context of literacies that impact their everyday lives. In fact, the recent teachers are not sufficiently equipped with media literacy as they are not born digitally native. It takes quite some efforts to have these Generation $\mathrm{X}$ or $\mathrm{Y}$ to catch up with their students who are born digital native or the Generation Z.

Lembaga Bahasa dan Pendidikan Profesional (LBPP) LIA has the passion of always keeping update with the latest approach and methodology in the English teaching and learning. As one of the efforts, the institution utilizes materials that combine traditional classroom and technology based media. It is Smart Choice Series written by Ken Wilson from Oxford University Press. These series of books adopted the Common European Framework of Reference (CEFR). The book was firstly officially used in Term IV of 2013 by all branches of LBPP LIA all over Indonesia. The materials are completed with audio, video and online practice for students. During the teaching and learning process, a laptop and the screen, speakers, and WIFI or LAN network are necessary. These materials have been used all over Indonesia for almost four years by all LBPP LIA. The evaluation time or the usage is one step ahead because the contract ending is nearing. Therefore, this research tries to investigate the utilizations of iTools' features by the teachers in terms of their knowledge and the utilization frequency.

\section{LITERATURE REVIEW}

\section{A. Blended Learning}

Blended learning in Eduviews AK-12 Leadership Series [2] is defined as the teaching practice that combines teaching methods from both face-to-face and online learning, is an established, rapidly growing instructional model that is proving highly effective in helping schools and districts address the challenges of students achievement, limited resources, and the expectations of $21 \mathrm{st}$ century learners. Blended learning is implemented in a variety of ways, ranging from models in which curriculum is fully online with face-to-face interaction to models in which face-to-face classroom instruction is integrated with online components that extend learning beyond the classroom or school day. The variety is shown in Fig. 1. 


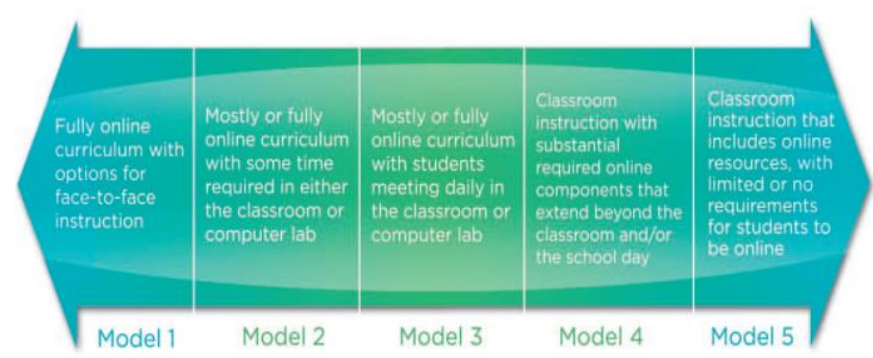

Fig. 1. The Continuum of Blended Learning Models

Some types and examples of Blended Learning are outlined in the Table I as presented by Suprihatin [3].

TABLE I. TyPES AND EXAMPLES OF BLENDED LEARNING

\begin{tabular}{|c|c|}
\hline $\begin{array}{l}\text { Live face-to-face (formal) } \\
\text { - } \quad \text { Instructor-led classroom } \\
\text { - } \quad \text { Workshops } \\
\text { - } \quad \text { Coaching/mentoring } \\
\text { - } \quad \text { On-the-job (OTJ) training }\end{array}$ & $\begin{array}{l}\text { Live face-to-face (informal) } \\
\text { - } \quad \text { Collegial connections } \\
\text { - } \quad \text { Work teams } \\
\text { - } \quad \text { Role modeling }\end{array}$ \\
\hline $\begin{array}{l}\text { Virtual collaboration/synchronous } \\
\text { - Live e-learning classes } \\
\text { - E-mentoring }\end{array}$ & $\begin{array}{l}\text { Virtual collaboration/asynchronous } \\
\text { - } \quad \text { Email } \\
\text { - Online bulletin boards } \\
\text { - } \quad \text { List servs } \\
\text { - Online communities }\end{array}$ \\
\hline $\begin{array}{l}\text { Self-paced learning } \\
\text { - Web learning modules } \\
\text { - Online resource links } \\
\text { - Simulations } \\
\text { - Scenarios } \\
\text { - Video and audio CD/DVD } \\
\text { - Online self-assessments } \\
\text { - Workbooks }\end{array}$ & $\begin{array}{ll}\text { Performance support } \\
\text { - } & \text { Help system } \\
\text { - } & \text { Print job aids } \\
\text { - } & \text { Knowledge databases } \\
\text { - } & \text { Documentation } \\
\text { - } & \text { Performance/decision support tools }\end{array}$ \\
\hline
\end{tabular}

\section{B. Smart Choice iTools}

Smart Choice Second Edition used by LBPP LIA is a fourskill course for adult and young adult learners. The series stresses on improving the ability to communicate in English. Each level contains 60-90 hours of classroom material and in LBPP LIA, the coverage of the materials is in $18-20$ sessions and each meeting is timed 120 minutes.

According to Wilson [4], Smart Choice iTools from Oxford University Press is a CD-ROM-based software program that transforms each Student Book into a media-rich classroom presentation tool. The design of iTools helps teachers navigate easily from page to page. iTools is compatible with all interactive whiteboard hardware and can also be used with a computer and data projector. In general, the iTools includes classroom video segments, embedded answer key and audio scripts, easy-to-use tool bar, Resources tab, and variety of audio, video, and PowerPoint media.

\section{C. iTools' Features}

- Resources is a library of photos, worksheets, and PowerPoint presentations inviting teachers to customize dozens of resources for classroom presentation and student practice. On the left side of the page, the Resources tab is located.

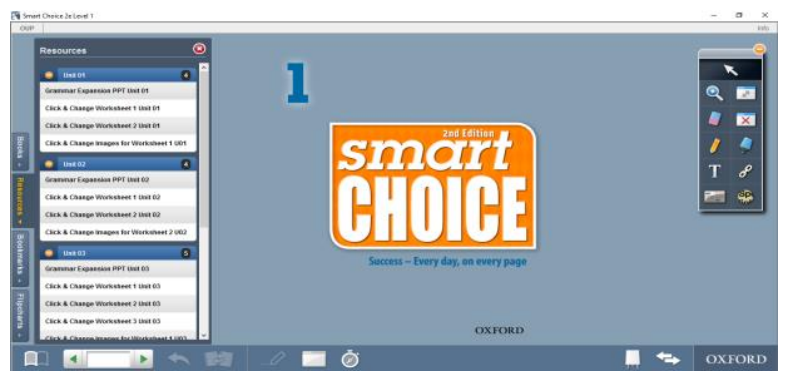

Fig. 2. On the left side of the page

- Bookmark is a feature which can be used by the teacher to keep a page from the Smart Choice iTools

- Flipcharts is pad of blank sheet and is used to write something as it functions like a whiteboard

- Back Arrow is used when one needs to go back to the previous page

- Drawings allows the user to write or to draw on the screen without exiting the Smart Choice iTools.

- Timer is stopwatch available to use for counting upwards from zero and measuring elapsed time without exiting the page as below:

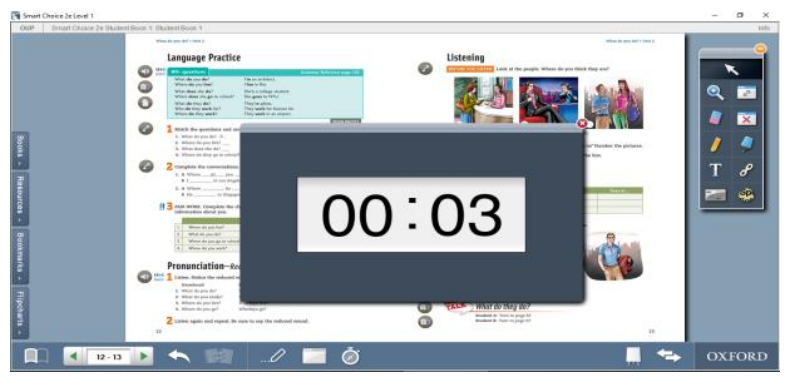

Fig. 3. Timer is stopwatch available

- Flip Control is a button to help modifying the position of some features whether it is right-or-left-oriented.

- Navigate Tool is a feature to move the page upward and downward or to the left and to the right. The Navigate Tool is the arrow sign on the upper right part.

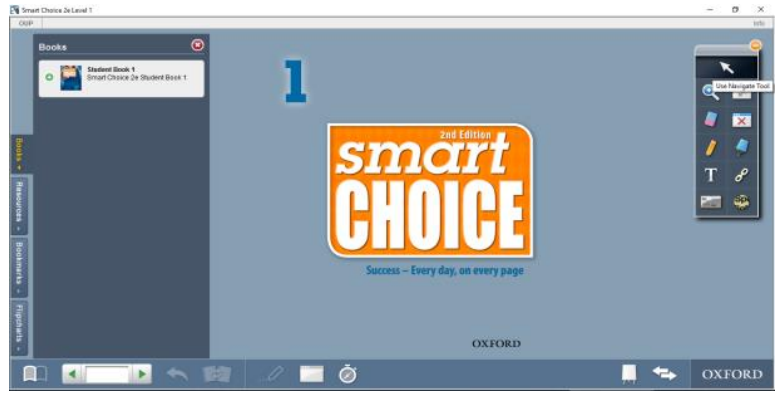

Fig. 4. Navigate Tool 
- Zoom Tool and Reset Zoom Tool are similarly used to enlarge the page or a part of the page.

- Eraser Tool is used for removing writing from the screen.

- Clear Screen is a feature to have the screen blank after being used.

- Pen Tool is the pen which can be used to write or draw either on the blank screen (flipcharts) or the page screen.

- Highlight Tool is used to give marks or color to a certain part of the screen

- Add Note is a feature that can be used to insert note or reminder on the page

- Add Web Link serves as inserted note that can be linked directly to browser supported by internet connection. The chain on the picture below shows the Web Link.

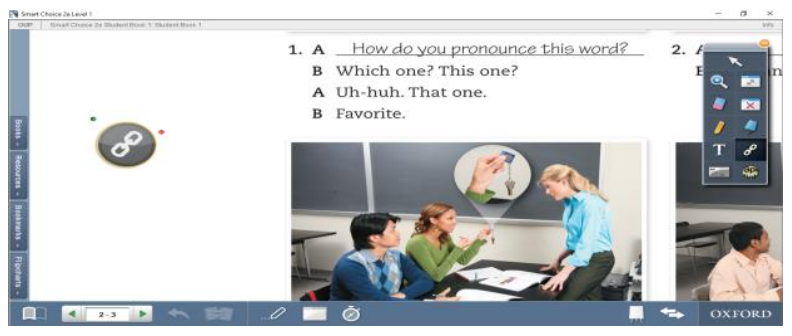

Fig. 5. The chain on the picture below shows the Web Link

- Screenshade Tool is needed when one has to cover a whole page or a part of the page only.

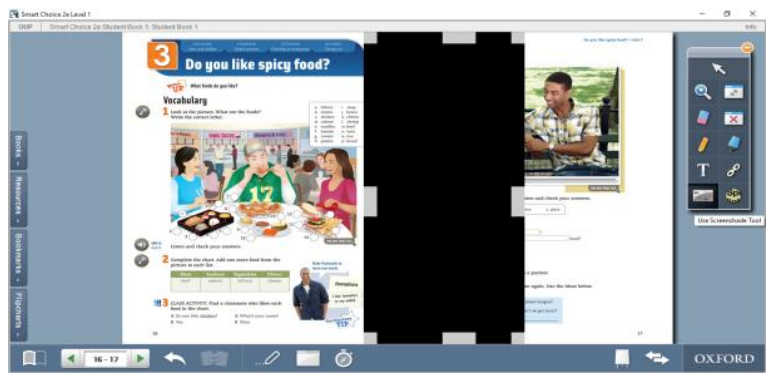

Fig. 6. Screenshade Tool

- Spotlight Tool is utilized or spotlighting certain part only without presenting other parts as below:

Fig. 7. Spotlight Too

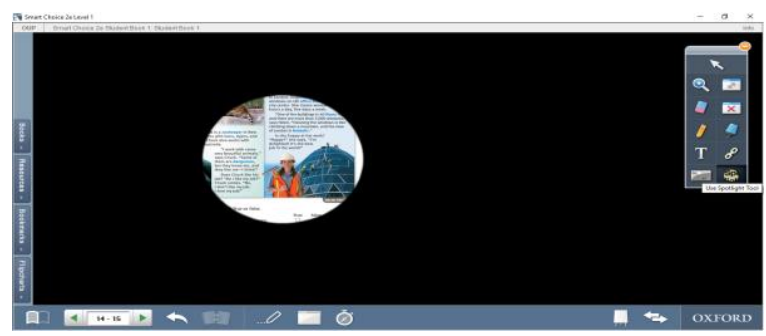

- Online Practice is designed for students to use outside class, includes interactive vocabulary, grammar, conversation, and video activities, and provides automatic scoring and feedback.

The Bookmark, Flipcharts, Back Arrow, Drawings and other features can be seen from this screenshot:

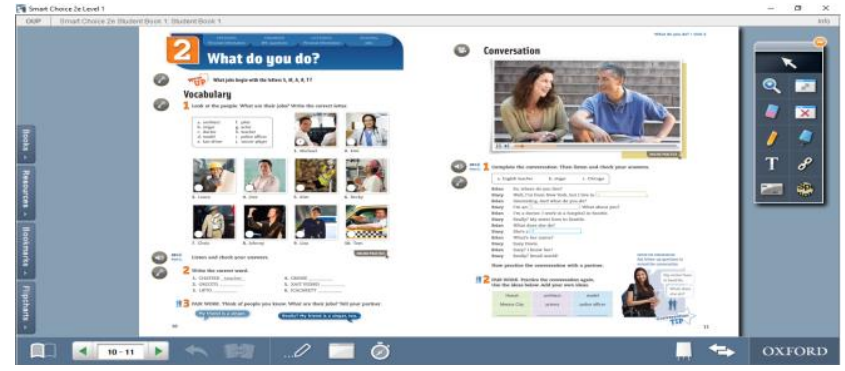

Fig. 8. The Bookmark, Flipcharts, Back Arrow, Drawings and other features

\section{Smart Choice Online Practice}

It is a student's password-protected access to online practice activities that covers grammar, vocabulary, videobased listening comprehension, and record-and-playback speaking activities. The audio for Student Book and Workbook is also provided and downloadable from this access. To make it more complete, instant feedback is provided when the student requests feedback on his/her work at any time to assess and track his/her own progress. As for the classroom teacher, s/he can anytime monitor and track student, class and institutional progress.

\section{METHOD}

This is a quantitative research by taking small scaled survey as the technique of data collection. The population is all teachers of LBPP LIA Banjarmasin and Banjarbaru. There are 26 of them. The questionnaire as the research instrument was given to 14 respondents which means it takes a bit more than $50 \%$ of the total population. The sampling technique was the random one depending on the teachers' willingness and availability to participate in the study. The teachers who filled out the questionnaire were those who have been teaching in LBPP LIA for 20 years, 10 years, 5 years, and 1 year. Seven out of fourteen are teachers from the latest recruitment in 2016.

\section{RESULT}

The investigation on the teachers' knowledge of Smart Choice's iTools is focusing on whether the teachers knows how to utilize the features of Smart Choice iTools. It is discovered that Resources tab, Navigate Tool, Zoom Tool, Reset Zoom Tool, Eraser Tool and Pen Tool are the features mostly utilized by the teachers. The second to the highest frequency used features are Back Arrow, Highlight Tool and Add Note. Clear screen, Drawings, Timer and Spotlight Tools are the next features which are understood by the teachers in term of usage. Some other features which are not quite utilized by half of the teachers are Bookmark, Flipcharts, Flip Control, 
Add Web Link, Screenshade Tool, and Online Practice. The detail findings can be seen in Table II.

TABLE II. THE TEACHERS’ KNOWLEDGE OF ITOOLS’ FEATURES FROM SMART CHOICE SERIES

\begin{tabular}{|l|l|l|}
\hline \multicolumn{1}{|c|}{ Feature } & Yes & \\
\hline Resources & 14 & 0 \\
\hline Bookmark & 6 & 8 \\
\hline Flipcharts & 6 & 8 \\
\hline Back Arrow & 13 & 1 \\
\hline Drawings & 11 & 3 \\
\hline Timer & 11 & 3 \\
\hline Flip Control & 9 & 5 \\
\hline Navigate Tool & 14 & 0 \\
\hline Zoom Tool & 14 & 0 \\
\hline Reset Zoom Tool & 14 & 0 \\
\hline Eraser Tool & 14 & 0 \\
\hline Clear Screen & 12 & 3 \\
\hline Pen Tool & 14 & 0 \\
\hline Highlight Tool & 13 & 1 \\
\hline Add Note & 13 & 1 \\
\hline Add Web Link & 8 & 6 \\
\hline Screenshade Tool & 6 & 8 \\
\hline Spotlight Tool & 11 & 3 \\
\hline Online Practice & 9 & 4 \\
\hline
\end{tabular}

The most familiar features of Smart Choice iTools to the teachers are due to the high usage frequency. They serve highly as navigation tools that are merely on click every time the screen page is changed. Those less utilized features such as Bookmark, Flipcharts, Flip Control, Add Web Link, Screenshade Tool are not in favor due to the possibility of using the features in every teaching. Bookmark isn't considered primarily necessary because every page needed can easily and directly be clicked without having to find the bookmarks first. Bookmark and Add Web Link tab can actually be utilized together when a web link is added and a bookmark is needed. Flipcharts, Flip Control, and Screenshade Tool can maximally be used when the teachers manipulate an activity that requires the students or the teachers themselves to write something or when a part is needed to specially be displayed.

The Online Practice is also rarely taken as advantages in enriching the students' material or as follow up activity outside the classroom because the students mostly admit that they don't have time and/or sufficient internet connection to access the self-online practice. There must be an alternative that instead of being assigned as homework, the online practice could be done in the classroom if the institution's internet facility supports. However, this might bring another new problem which is related to the materials' coverage of the term or semester.

In exploiting the Smart Choice iTools, the teachers vary their utilization depending on the need. Navigate Tool, Zoom Tool and Reset Zoom Tool are tabs which are always used by 7 to 8 teachers. None of the samples stated that they never used these features as it can be seen in Table III. Other features which are utilized by most teachers are Back Arrow, Zoom Tool, Reset Zoom Tool, Eraser Tool and Clear Screen. None of the teachers mentioned that they never utilized these features.
TABLE III. THE UTILIZATION OF SMART CHOICE ITOOLS

\begin{tabular}{|c|c|c|c|c|c|c|}
\hline \multirow[b]{2}{*}{ Feature } & \multicolumn{6}{|c|}{ Frequency Of Utilization } \\
\hline & $\frac{\tilde{z}}{\hat{z}}$ & 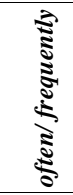 & 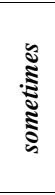 & 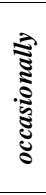 & 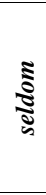 & 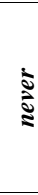 \\
\hline Resources & 4 & 1 & 4 & 2 & 2 & 1 \\
\hline Bookmark & & & 1 & 1 & 2 & 2 \\
\hline Flipcharts & 1 & & 4 & & & \\
\hline Back Arrow & 2 & 9 & 1 & 1 & & \\
\hline Drawings & & & 3 & 1 & 4 & 3 \\
\hline Timer & & 2 & 2 & 2 & 3 & 2 \\
\hline Flip Control & & 2 & 2 & 1 & 2 & 2 \\
\hline Navigate Tool & 8 & 4 & 1 & 1 & & \\
\hline Zoom Tool & 7 & 5 & 1 & & & \\
\hline Reset Zoom Tool & 7 & 4 & 2 & 1 & & \\
\hline Eraser Tool & 2 & 2 & 2 & 4 & 4 & \\
\hline Clear Screen & 2 & 2 & 2 & 1 & 5 & \\
\hline Pen Tool & 1 & 1 & 5 & 1 & 2 & 4 \\
\hline Highlight Tool & 1 & 1 & 4 & & 1 & 4 \\
\hline Add Note & & & 2 & 4 & 1 & 6 \\
\hline Add Web Link & & & & 2 & 2 & 4 \\
\hline Screenshade Tool & & & & 2 & 1 & 3 \\
\hline Spotlight Tool & & 1 & 4 & 2 & 2 & 1 \\
\hline Online Practice & 1 & 1 & 3 & 2 & 2 & 3 \\
\hline
\end{tabular}

The features which are not frequently used by the teachers are Bookmark, Flipcharts, Drawings, Add Note, Add Web Link, Screenshade Tool and Spotlight Tool. This might due to several reasons. First, the teachers do not find the necessity for using the features such as Bookmark and Flipcharts. Second, it is probably because the teachers are lack of knowledge in maximally making use of the features. As for Online Practice, it could mostly be due to the internet facility and time allocation.

\section{CONCLUSION}

The innovation in EFL teaching and learning which is so called blended learning might encounter various challenges in term of knowledge and the management of utilization. As for Smart Choice iTools, teachers' lack of knowledge might hamper the utilization of the iTools. The exploitation must also be supported by the facility especially internet connection. Moreover, teachers' creativity is mostly needed in blending the non-technology based procedures with the technology based one.

\section{ACKNOWLEDGMENT}

This research is dedicated to LBPP LIA which have always innovated its' English as a Foreign Language (EFL) teaching and learning. The highest gratitude goes to the samples of the study for their help in taking the survey.

\section{REFERENCES}

[1] Stacie L. Tate "Media Literacy in Handbook of Research on Teaching the English Language Arts (Third Edition). Eds. Diane Lapp \& Douglas Fisher," New York and London: Routledge Taylor \& Francis Group. 2011, pp. 182-187. 
[2] . "Blended Learning: Where Online and Face-to-Face Instruction Intersect for 21st Century Teaching and Learning" in Eduviews A K-12 Leadership Series. Washington: Blackboard Inc. 2009

[3] M. Suprihatin, "An Overview of Blended Learning," PPT presented on June $27^{\text {th }}$ 2011. unpublished.

[4] Stacey, E. and Gerbic, P. "Success Factors for Blended Learning. In Hello! Where Are You in The Landscape of Educational Technology?" Proceedings ascilite Melbourne 2008. http://www.ascilite.org.au/conferences/melbourne08/procs/stacey.pdf
[5] Fakeye, David O. (2010). Assessment of English language teachers' knowledge and use of information and communication technology (ICT) in Ibadan Southwest local government of Oyo State in AmericanEurasian Journal of Scientific Research 5 (4): 270-276.

[6] Alkhanak and Azmi. (2011). Information Technology Usage And Attitudes Towards Online Resources- Students Perspective.

[7] Ken Wilson "Smart Choice Teacher Book-Second Edition." New York: Oxford University Press. 2011 